\title{
Delayed breast feeding initiation increases the odds of colostrum avoidance among mothers in Northwest Ethiopia: a community-based cross-sectional study
}

\author{
Maezu G/slassie ${ }^{1}$, Zelalem Nigussie Azene ${ }^{2^{*}}$ (D), Abuhay Mulunesh ${ }^{2}$ and Tesfa Sewunet Alamneh ${ }^{3}$
}

\begin{abstract}
Background: Colostrum is a yellowish and sticky breast milk produced in late pregnancy. Annually, $60 \%$ of 10.9 million under-five deaths globally are due to malnutrition. Of these, over two-thirds of the deaths are accounted by sub-optimal feeding practices in the first year of life, including colostrum discarding. However, evidence on the magnitude of colostrum avoidance and its associated factors at the community level is very limited in Ethiopia, particularly in the study area.

Thus, this study aimed to assess the magnitude of colostrum avoidance and associated factors among mothers who gave birth in the last six months in Gozamen district, northwest Ethiopia, 2019.

Methods: A community-based cross-sectional study was conducted among 741 (741) mothers who gave birth in the last six months in Gozamen district from August 1 to September 12, 2019. A stratified cluster sampling technique was used to select the study participants. Data were collected by face-to-face interviewer-administered, pretested, and semi-structured questionnaire. Binary logistic regressions (bi-variable and multivariable) were fitted to identify statistically significant variables. Adjusted Odds Ratio (AOR) with 95\% Confidence Interval (Cl) was used to declare statistically significant variables on the basis of $p$-value $<0.05$ in the multivariable binary logistic regression.

Results: This study indicated that the magnitude of colostrum avoidance was $22.1 \%$ (95\% Cl, 19.0, 25.2\%). Mothers who did not get counseling on timely initiation of breast feeding ( $A O R=3.91[95 \% \mathrm{Cl}, 1.98,7.72])$, not participate in pregnant woman forum $(\mathrm{AOR}=2.59[95 \% \mathrm{Cl}, 1.30,5.14])$, initiate breast-feeding lately (more than $1 \mathrm{~h}$ ) (AOR 2.27[95\% Cl, 1.18, 4.34]), and those having unfavorable attitude towards colostrum feeding ( $\mathrm{AOR}=7.35[95 \% \mathrm{Cl}$, $3.89,13.91])$ were factors associated with the increased likelihood of colostrum avoidance. However, institutional delivery (AOR; $0.06[95 \% \mathrm{Cl}, 0.02,0.19])$ and prelacteal feeding (AOR; $0.10[95 \% \mathrm{Cl}, 0.05,0.21]$ ) were predictors associated with reduced likelihood of colostrum avoidance.

(Continued on next page)
\end{abstract}

\footnotetext{
* Correspondence: zniqussie35@gmail.com

²Department of Women's and Family Health, School of Midwifery, College of Medicine and Health Sciences, University of Gondar, Gondar, Ethiopia

Full list of author information is available at the end of the article
}

(c) The Author(s). 2021 Open Access This article is licensed under a Creative Commons Attribution 4.0 International License, which permits use, sharing, adaptation, distribution and reproduction in any medium or format, as long as you give appropriate credit to the original author(s) and the source, provide a link to the Creative Commons licence, and indicate if changes were made. The images or other third party material in this article are included in the article's Creative Commons licence, unless indicated otherwise in a credit line to the material. If material is not included in the article's Creative Commons licence and your intended use is not permitted by statutory regulation or exceeds the permitted use, you will need to obtain permission directly from the copyright holder. To view a copy of this licence, visit http://creativecommons.org/licenses/by/4.0/. The Creative Commons Public Domain Dedication waiver (http://creativecommons.org/publicdomain/zero/1.0/) applies to the data made available in this article, unless otherwise stated in a credit line to the data. 
(Continued from previous page)

Conclusion: Colostrum avoidance is a common practice in the study area. Therefore, in order to reduce this practice, strengthening infant feeding counseling, promoting institutional delivery, timely initiation of breastfeeding, health education, and community advocating are recommended interventions. In addition, creating awareness on the benefits of colostrum feeding is very instrumental to tackle the practice of colostrum avoidance.

Keywords: Colostrum avoidance, Discard, Associated factors, Woman who gave birth in the last six months, Ethiopia

\section{Background}

Colostrum is a yellowish and sticky breast milk produced in late pregnancy and in the first few days after delivery [1]. World Health Organization (WHO) recommends colostrum as the first perfect food for newborns and feeding should be started immediately within the first 1 after delivery. It is considered as the first immunization for newborns and plays a great role in the immunological defense of newborn infants [2-4]. Colostrum feeding to a newborn is important to decrease the risk of undernutrition among young children [5]. Despite colostrum feeding provides newborns with immunity to infection, mothers in many developing countries still discard colostrum because of traditional beliefs such as viewing it as unclean and dirty milk having no nutritional value, to dilute to be useful, or seeing it as bad lucks for the family [6, 7]. Breast Feeding (BF) is the way of providing ideal food for infants to enhance their growth and development [8]. WHO and United Nations Children's Emergency Fund (UNICEF) recommends breastfeeding immediately within $1 \mathrm{~h}$ after delivery, colostrum feeding, Exclusive Breast Feeding (EBF) for children up to six months of age, and sustained breastfeeding up to 24 months or above [2].

Colostrum avoidance (CA) is the discarding of colostrum during the first five days after birth [9]. Different studies indicated that sub-optimal breastfeeding like CA practice increases the risk of morbidities like diarrhea, pneumonia, Acute Respiratory Infections (ARI), and mortality among infants [10-12]. In addition, it increases the chance of Prelacteal Feeding (PLF) [13-15], barrier for Timely Initiation of Breast Feeding (TIBF), and Exclusive Breast Feeding (EBF) $[6,16,17]$.

Globally, $60 \%$ of 10.9 million under-five children died every year directly or indirectly due to malnutrition and over two-thirds of the deaths are accounted for by inappropriate feeding practices that occurred in one year of life [2]. Sub-optimal breastfeeding in developing countries is responsible for $45 \%$ of neonatal deaths, $30 \%$ of diarrheal deaths, $18 \%$ of acute respiratory deaths in children $[18,19]$.

In Sub-Saharan Africa (SSA) and Southern Asia, under-five deaths are high which is 16 times more than in developed countries [20]. Furthermore, child mortality due to diarrhea is high in SSA countries including
Ethiopia. Provision of colostrum for newborns, timely initiation of breast feeding, and exclusive breast feeding are among the preventive strategies of diarrheal disease in children [21]. Optimal breastfeeding practices including colostrum feeding in early life prevents about $13 \%$ of under-five deaths [22].

In Ethiopia, colostrum deficiency in early life was one risk factor for under-five stunting [23]. The practice of colostrum feeding is hindered by different factors including maternal health service utilization and neonatal factors $[9,24,25]$. Breast feeding is practiced in all parts of Ethiopia as a universal practice, but according to the mini Ethiopian Demographic Health Survey (EDHS) 2019, the prevalence of EBF at 6 months was 59\%. There is still a gap in optimal breastfeeding practice [26] and in 2010, the national prevalence of colostrum avoidance was $39.8 \%$ [27]. Ethiopia has adopted the national Infant and Young Child Feeding (IYCF) guideline that discourages colostrum avoidance practice to attain optimal breastfeeding [28]. However, suboptimal feeding practice is documented after the implementation of the IYCF guideline. Colostrum avoidance is commonly practiced in different parts of Ethiopia. But, the reasons for it are not well studied in the country particularly in Gozamen district.

Furthermore, evidence on the magnitude of colostrum avoidance at the community level is very limited in Ethiopia. Therefore, the aim of this study was to assess the magnitude of colostrum avoidance and associated factors among mothers who gave birth in the last six months in Gozamen district, northwest Ethiopia.

\section{Methods}

\section{Study design, setting, and period}

A community-based cross-sectional study was conducted from August 1 to September 12, 2019, in Gozamen district. Gozamen district is one of the 18 districts in East Gojjam zone. Debre Markos is the zonal capital city of East Gojjam zone. It is located $300 \mathrm{kms}$ away from Addis Ababa, the capital city of Ethiopia and, about $260 \mathrm{kms}$ from Bahir Dar, the capital of Amhara regional state. The district is divided into 30 kebeles for administrative purpose (the smallest administrative unit next to the district in Ethiopia). Of these, 5 are urban and 25 are rural kebeles. According to the district administrative report, 
the population size of the district is estimated to be 164, 816. Among these, about 82,573 are women, of those, 2536 are mothers who gave birth in the last six months. The district has now 6 health centers and 26 health posts providing health services to the population.

\section{Population}

All mothers who gave birth in the last six-months in Gozamen district were the source population whereas those mothers who gave birth in the last six months in the selected kebeles/clusters of the district were the study population.

\section{Eligibility criteria}

\section{Inclusion criteria}

All mothers who lived in Gozamen district for at least 6 months and gave birth in the last six months were included in the study.

\section{Exclusion criteria}

Those mothers who were seriously ill and unable to respond at the time of data collection were excluded from the study.

\section{Sample size determination and sampling procedure}

The sample size was determined for the first and second objectives. Finally, the largest sample size was taken. Single population proportion was used to calculate the sample size for the first objective by considering the following assumptions:

Proportion $=12 \%$ [25], confidence level (CI), 95\%, and margin of error $=4 \%$.

Using the following single proportion formula:

$$
\frac{\mathbf{n}=(\mathbf{z \alpha} / 2) 2 \mathbf{p}(1-\mathbf{p})}{\mathrm{d} 2} \quad \frac{\mathbf{n}=(1.96) 2(0.12(1-0.12)}{(0.04) 2}=253
$$

Where $\mathrm{n}=$ required sample size, $\mathrm{Z}=$ critical value for normal distribution at 95\% confidence level (1.96), $\mathrm{P}=$ Proportion of colostrum avoidance, $\mathrm{d}=0.04(4 \%$ margin of error). By considering a $10 \%$ non-response rate and a design effect of 2 the sample size was 560 . For the second objective, the sample size was calculated using Epi info version 7.2 (double population proportion) using significant variables obtained from the previous study and the calculated sample size was greater than the first objective. Lastly, the larger sample size was taken (754). However, as stratified cluster sampling technique was employed to select the study participants the final sample size became 741. First, the population was stratified by residence as urban and rural Kebeles. The residential stratification gave 25 rural and 5 urban kebeles. Out of those, two urban and 7 rural kebeles were selected randomly by using a lottery method. Finally, all the selected kebeles were used as clusters, and all households in the selected Kebeles were included. Either of the mothers was interviewed in households having two mothers who gave birth in the last six months in the district. Households closed during the data collection period were revisited.

\section{Study variables and measurements}

Colostrum avoidance is the response variable, whereas others like socio-demographic, maternal health service utilization, breastfeeding, obstetrical related characteristics, and maternal behavior-related variables are independent variables included in this study. Colostrum avoidance was considered as yes if the woman responded "Yes" when asked whether she discarded colostrum before giving breast to the infant within 5 days after delivery otherwise considered as no [9].

\section{Data collection tool and procedures}

Data were collected using a pretested, semi-structured, and interviewer-administered questionnaire. The questionnaire was developed after reviewing relevant literatures. It was prepared originally in English and translated into the local language (Amharic) for the purpose of data collection and then it was translated back to English to maintain the consistency of the tool. The questionnaire has socio-demographic variables, health service utilization variables, obstetrics related variables, and maternal behavior related questions, breast feeding related variables and, wealth index related variables. For data collection, six Health Extension Workers (HEW) were involved under the supervision of the investigators and supervisors.

\section{Data quality control}

A one-day training was given for data collectors and supervisors. The data were daily checked for completeness and accuracy by the principal investigator and supervisors.

A pretest was conducted on $5 \%$ of the sample size in the non-selected kebele of the district (Myanigetam) to ensure the validity, reliability, and clarity of the data collection instrument. Based on the findings from the pretest, modification on the questionnaire was done, and arrangement of questions was revised.

\section{Data analysis}

Data were coded, cleaned, and entered into Epi data version 4.4.1 software. The data were exported to Statistical Package for Social Science (SPSS) version 20 for data analysis. Descriptive statistics (like median, interquartile range, frequencies, and percentages) were used to describe the study population in relation to dependent and independent variables. Results were presented in text, tables, and figures. Principal Component Analysis 
(PCA) was performed for urban and rural Kebeles separately to classify the household asset into low, middle, and high wealth indexes.

Binary logistic regression (bivariable and multivariable logistic regression) was used to identify statistically significant independent variables and independent variables having a $p$-value less than 0.2 in the bi-variable analysis were entered into multi-variable binary logistic regression. A $p$-value $<0.05$ in the multivariable analysis was used to declare statistically significant variables. Hosmer-Lemeshow goodness-of-fit was used to test model fitness and declared good fitted at a p-value of $>0.05$. An AOR with $95 \% \mathrm{CI}$ was reported to show the strength of associations among the independent variables and colostrum avoidance.

\section{Results}

Sociodemographic characteristics of the respondents

A total of 741 mothers who gave birth in the last six months were interviewed with a $100 \%$ response rate. The median age of the respondents was 30 years with (IQR \pm 10 years) and the median age of their child was 3 months with (IQR \pm 3 months. Majority, (93.1\%) of the respondents were married. Five hundred sixty-six (82\%) of husbands' occupation was farmer. Regarding educational status, 289 (41.9\%) of husbands had no formal education. Three hundred seventy-eight (51\%) of mothers had no formal education. Nearly two-thirds $(65.7 \%)$ of the respondents' occupation was a farmer. Almost all respondents (99.5\%) and (99.6\%) belongs to orthodox by religion and Amhara by ethnicity, respectively (Table 1 ).

\section{Obstetrics and maternal behavioral related characteristics of the respondents}

Regarding parity, three-fourths $(75.4 \%)$ of the study participants were multiparous, and more than half $(58 \%)$ had optimal birth spacing (greater or equal to 24 months). About 508 (68.4\%) of mothers had good knowledge about colostrum feeding and more than two-thirds of respondents (72.2\%) had favorable attitude towards colostrum feeding (Fig. 1).

\section{Health care service utilization of the study participants}

Concerning health care service utilization of the respondents, about 660 (89.1\%) of the respondents had ANC follow-up. Out of these, 444 (67.3\%) had less than four visits. Three hundred thirteen $(47.4 \%)$ were counseled about breastfeeding. Of those, 121(38.7\%) were counseled about exclusive breastfeeding. Majority of the study participants (88.9\%) had institutional delivery. Out of the total respondents, 419 (56.6\%) of mothers had participated in pregnant woman forum (Table 2).

\section{Breast feeding-related characteristics}

One hundred sixty-four (22.1\%) of the respondents discarded colostrum within five days after delivery. One hundred twenty-even (17.1\%) of mothers had practiced pre-lacteal feeding. The most common pre-lacteal feeding was butter (81.1\%) (Table 3).

\section{Factors associated with colostrum avoidance}

$\mathrm{Bi}$-variable and multi-variable binary logistic regression were done to identify factors associated with colostrum avoidance. In bi-variable analyses, age of women, husband's occupation, access to TV, breastfeeding counseling during ANC, place of delivery, PNC visit, breastfeeding counseling on timely initiation, participation in pregnant woman forum, prelacteal feeding, time of initiation of breastfeeding, and attitude towards colostrum had association with colostrum avoidance. Only participation in pregnant woman forum, place of delivery, time of breast feeding initiation, pre-lacteal feeding, breastfeeding counseling on timely initiation, and attitude of mothers towards colostrum were significantly associated with colostrum avoidance in multi-variable binary logistic regression analysis.

Mothers who did not get counseling on timely initiation of BF were 3.9 times more likely to avoid colostrum $(\mathrm{AOR}=3.91[95 \% \mathrm{CI}, 1.98,7.72])$ than those respondents who did get counseling. Women who failed to participate in pregnant woman forums were 2.59 times more likely to discard colostrum $(\mathrm{AOR}=2.59$ [95\% CI, 1.30, 5.14]) as compared to their counterparts. The odds of colostrum avoidance were 2.27 times higher in individuals who initiated breastfeeding in more than one Hr. (AOR 2.27[95\% CI, 1.18, 4.34]) as compared to their counterparts.

In addition, the odds of colostrum avoidance was 7.35 times higher in mothers who had an unfavorable attitude towards colostrum (AOR $=7.35[95 \% \mathrm{CI} ; 3.89,13.91]$ ) as compared to their counterparts. Respondents who gave birth at health facilities were $94 \%$ times less likely to discard colostrum (AOR; 0.06[95\% CI, 0.02, 0.19]) as compared to mothers who gave birth at home. Those mothers who did not give pre lacteal feeding were $90 \%$ times less likely to discard colostrum (AOR; 0.10 [95\% CI; $0.05,0.21]$ ) as compared to those respondents who gave prelacteal feeding (Table 4).

\section{Discussion}

Even though WHO, global and national IYCF guidelines recommended that all newborns should start breastfeeding immediately (within the first $1 \mathrm{~h}$ after delivery) and encouraged colostrum feeding [2], colostrum is still discarded in different parts of the globe, particularly in Ethiopia [6, 7]. Furthermore, evidence on the magnitude of colostrum avoidance at the community level is very limited in the country, especially in the study area. As such, the current study was conducted to determine the magnitude of colostrum avoidance and to identify the 
Table 1 Socio-demographic characteristics of mothers who gave birth in the last six months in Gozamen district, East Gojjam zone, North West Ethiopia, $2020(n=741)$

\begin{tabular}{|c|c|c|c|}
\hline Variables & Category & Frequency $(n)$ & Percent (\%) \\
\hline \multirow[t]{2}{*}{ Residence } & Urban & 98 & 13.2 \\
\hline & Rural & 643 & 86.8 \\
\hline \multirow[t]{2}{*}{ Sex of child } & Male & 343 & 46.3 \\
\hline & Female & 398 & 53.7 \\
\hline \multirow[t]{3}{*}{ Age of respondent } & $15-25$ Years & 162 & 21.9 \\
\hline & 26-35 Years & 375 & 50.6 \\
\hline & $36-45$ Years & 204 & 27.5 \\
\hline \multirow[t]{3}{*}{ Age of child } & $0-1$ month & 165 & 22.3 \\
\hline & $2-3$ month & 290 & 39.1 \\
\hline & $4-6$ month & 286 & 38.6 \\
\hline \multirow[t]{2}{*}{ Family size } & $\leq 3$ & 182 & 24.6 \\
\hline & $\geq 4$ & 559 & 75.4 \\
\hline \multirow[t]{2}{*}{ Number of children } & $\leq 3$ & 565 & 76.2 \\
\hline & $\geq 4$ & 176 & 23.8 \\
\hline \multirow[t]{5}{*}{ Marital status of the woman } & Single & 26 & 3.5 \\
\hline & Married & 690 & 93.1 \\
\hline & Widowed & 9 & 1.2 \\
\hline & Separated & 3 & 0.4 \\
\hline & Divorced & 13 & 1.8 \\
\hline \multirow[t]{5}{*}{ Educational status of the husband $(n=690)$} & Unable to write and read & 289 & 41.9 \\
\hline & Able to write and read & 206 & 29.8 \\
\hline & Primary school & 129 & 18.7 \\
\hline & Secondary school & 51 & 7.4 \\
\hline & College and above & 15 & 2.2 \\
\hline \multirow[t]{4}{*}{ Occupational status of the husband $(n=690)$} & Farmer & 566 & 82 \\
\hline & Merchant & 43 & 6.2 \\
\hline & Governmental and private employee & 63 & 9.1 \\
\hline & Daily laborer & 18 & 2.7 \\
\hline \multirow[t]{6}{*}{ Occupational status of the woman } & Housewife & 175 & 23.6 \\
\hline & Merchant & 22 & 3 \\
\hline & Private and governmental employee & 31 & 4.2 \\
\hline & Farmer & 487 & 65.7 \\
\hline & Daily labour & 19 & 2.6 \\
\hline & Student & 7 & 0.9 \\
\hline \multirow[t]{5}{*}{ Educational status of the woman } & Unable to read and write & 378 & 51.0 \\
\hline & Able to write and read & 176 & 23.8 \\
\hline & Primary school (1-8) & 127 & 17.1 \\
\hline & Secondary school (9-12) & 44 & 5.9 \\
\hline & College and above & 16 & 2.2 \\
\hline \multirow[t]{2}{*}{ Access to radio } & Yes & 417 & 56.3 \\
\hline & No & 324 & 43.7 \\
\hline \multirow[t]{2}{*}{ Access to television } & Yes & 60 & 8.1 \\
\hline & No & 681 & 91.9 \\
\hline
\end{tabular}


Table 1 Socio-demographic characteristics of mothers who gave birth in the last six months in Gozamen district, East Gojjam zone, North West Ethiopia, 2020 ( $n=741)$ (Continued)

\begin{tabular}{|c|c|c|c|}
\hline Variables & Category & Frequency $(n)$ & Percent (\%) \\
\hline \multirow[t]{2}{*}{ Household head } & Yes & 57 & 7.7 \\
\hline & No & 684 & 92.3 \\
\hline \multirow[t]{3}{*}{ Wealth index of family } & Low & 256 & 34.5 \\
\hline & Medium & 238 & 32.2 \\
\hline & High & 247 & 33.3 \\
\hline
\end{tabular}

factors associated with it. This study showed that the magnitude of colostrum avoidance was found to be $22.1 \%$ (95\% CI, 19, 25.2). This finding (22.1\%) is higher than the studies conducted in rural areas of Mettu district $17.5 \%$ [29], Raya kobo district $13.5 \%$ [30], and Arbaminch Zuria11\% [6]. This discrepancy might be due to socio-cultural and infant feeding styles that affect colostrum feeding since colostrum avoidance is traditional malpractice affected by the attitude and cultural beliefs of the community. In addition, this finding is higher than studies done in urban areas of Ethiopia such as; Axum town 6.3\% [9], North Wollo zone 12\% [25], Kombolicha town 11.4\% [31], and Bahir Dar city 16.7\% [32]. The possible explanation for the observed discrepancy could be due to differences among study settings. The earlier studies conducted in the urban parts of the country where there is better access to different information on infant feeding practices $[33,34]$.

The result of our study is in line with studies conducted in Motta 20.3\% [35] and Mizan Aman teaching hospital $23.7 \%$ [36]. This similarity might be due to similar sociocultural practices between the two settings. However, the prevalence of colostrum avoidance in this study is lower than studies carried out in Kossaye, rural northern Ethiopia 79\% [37], national prevalence of Ethiopia 38.9\% [27], Afambo, Afar regional state 35\% [5, 27],
Jimma Arjo Woreda 27.5\% [7], block RS Pura 76\% [38], Bhavnagar city, Gujarat India 63.1\% [39], Kamrup Assam, India 29.5\% [40], rural health training center Santhiram medical college Nandyal 90.6\% [12], Mansoura district in Egypt 57.8\% [41], and South Sudan 38.8\% [42]. The possible explanation may be due to the differences in the study population, socio-demographic characteristics, socio-culture, and year of study across studies.

Regarding factors associated with colostrum avoidance, mothers who did not get counseling on timely initiation of BF were 3.9 times more likely to discard colostrum as compared to their counterparts $(\mathrm{AOR}=3.91[95 \% \mathrm{CI}$; $1.98,7.72])$. This is consistent with a study done in Kombolicha town [31]. The possible explanation for this finding might be due to the fact that mothers who did not get counseling on timely initiation of BF have no knowledge of when to initiate BF, thus, they are liable to initiate BF lately, when they initiate breastfeeding lately, they will have enough time to discard colostrum due to miss information on colostrum feeding.

This study also showed that mothers who did not give prelacteal feeding were $90 \%$ times less likely to discard colostrum as compared to those respondents who gave prelacteal feeding (AOR; 0.10 [95\% CI; 0.05, 0.21]). This is supported by a study done in North Wollo zone [25]. The possible reason might be due to the fact that

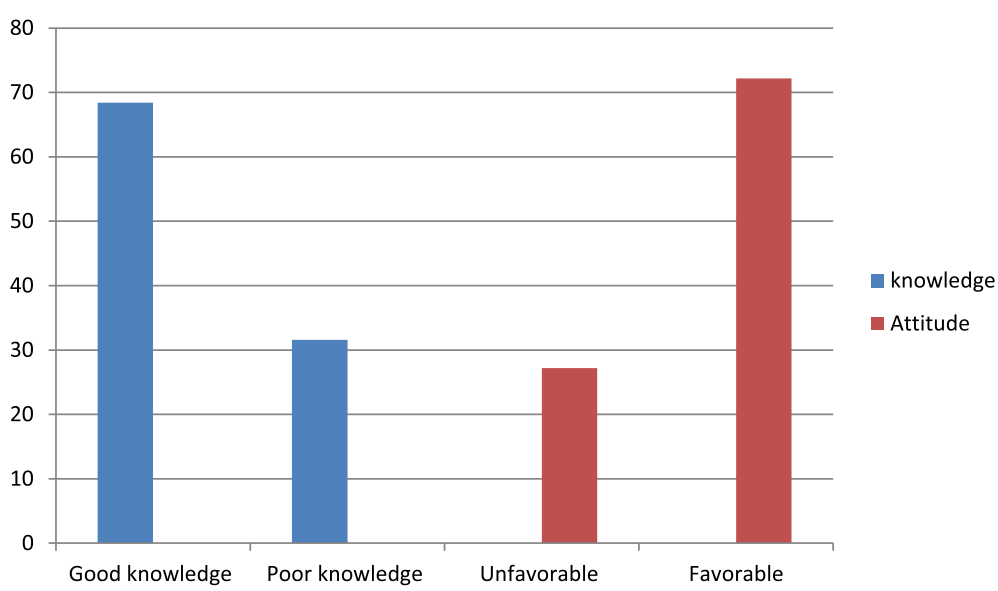

Fig. 1 Knowledge and attitude of mothers who gave birth in the last six months about colostrum feeding in Gozamen district, East Gojjam zone, North West Ethiopia, 2020 $(n=741)$ 
Table 2 Health care service utilization of mothers who gave birth in the last six months in Gozamen district, East Gojjam zone, North West Ethiopia, $2020(n=741)$

\begin{tabular}{|c|c|c|c|}
\hline Variables & Category & Frequency $(n)$ & Percent $(\%)$ \\
\hline \multirow[t]{2}{*}{ ANC visit $(n=741)$} & Yes & 660 & 89.1 \\
\hline & No & 81 & 10.9 \\
\hline \multirow[t]{2}{*}{ Number of ANC visit $(n=660)$} & $<4$ & 444 & 67.3 \\
\hline & $\geq 4$ & 216 & 32.7 \\
\hline \multirow[t]{2}{*}{ BF counseling at ANC $(n=660)$} & Yes & 313 & 47.4 \\
\hline & No & 347 & 52.6 \\
\hline \multirow[t]{7}{*}{ Counseling services } & Benefits of breastfeeding & 52 & 16.6 \\
\hline & Position during BF & 22 & 7.0 \\
\hline & EBF & 121 & 38.7 \\
\hline & Management of BF problems & 13 & 4.1 \\
\hline & Expression of breast milk & 18 & 5.8 \\
\hline & Colostrum benefits and should not discard & 61 & 19.5 \\
\hline & Others* & 26 & 8.3 \\
\hline \multirow[t]{2}{*}{ Place of delivery $(n=741)$} & Health facility & 666 & 89.9 \\
\hline & Home & 75 & 10.1 \\
\hline \multirow[t]{3}{*}{ Mode of delivery $(n=741)$} & Caesarian delivery & 67 & 9 \\
\hline & Spontaneous vaginal delivery & 659 & 88.9 \\
\hline & Instrumental delivery & 15 & 2.1 \\
\hline \multirow[t]{4}{*}{ Person assisted the labour $(n=741)$} & Health professional & 657 & 88.7 \\
\hline & Traditional birth attendant & 15 & 2.0 \\
\hline & Family (mother, husband) & 56 & 7.6 \\
\hline & Others ${ }^{* *}$ & 13 & 1.7 \\
\hline \multirow[t]{2}{*}{ PNC visit $(n=741)$} & Yes & 567 & 76.5 \\
\hline & No & 174 & 23.5 \\
\hline \multirow[t]{2}{*}{ BF counseling at PNC $(n=567)$} & Yes & 263 & 46.4 \\
\hline & No & 304 & 53.6 \\
\hline \multirow[t]{2}{*}{ Participation in pregnant woman forum } & Yes & 419 & 56.5 \\
\hline & No & 322 & 43.5 \\
\hline
\end{tabular}

Key: Others* = start Bf within one hr., avoid PLF, and feed their child 8-12 time per day

Others $^{* *}=$ mother, sister in law, and neighbor

mothers who did not give prelacteal feeding have no other options than colostrum as food for their children [42].

Furthermore, late initiation of breast feeding was another factor found significantly associated with colostrum avoidance practice. Mothers who initiated breastfeeding in more than $1 \mathrm{~h}$ were 2.27 times more likely to discard colostrum as compared to their counterparts (AOR 2.27[95\% CI; 1.18, 4.34]). This is consistent with studies conducted in North Wollo zone, Raya Kobo district, and systematic review done in Ethiopia [25, 30, 43], respectively. This might be explained as the time interval increases between delivery and breastfeeding initiation, there will be more time for infant feeding malpractices like colostrum avoidance [25].
The odds of colostrum avoidance was 2.59 times higher among mothers who did not participate in pregnant woman forum as compared to mothers who participated in pregnant woman forum $(\mathrm{AOR}=2.59[95 \% \mathrm{CI}$; $1.30,5.14])$. This may be due to the fact that participation in health education during pregnant woman forum will increase mothers' awareness towards colostrum feeding. This finding is comparable with a study carried out in Kombolicha town [25].

This study also revealed that mothers who gave birth in health institutions were 94\% times less likely to avoid colostrum as compared to mothers who gave birth at home (AOR; 0.06[95\% CI; 0.02, 0.19]). This is in line with studies conducted in North Wollo zone, Bhavnagar city, Raya Kobo district, and 
Table 3 Breastfeeding-related characteristics of mothers who gave birth in the last six months in Gozamen district, East Gojjam zone, North West Ethiopia, $2020(n=741)$

\begin{tabular}{|c|c|c|c|}
\hline Variables & Category & Frequency $(n)$ & Percent (\%) \\
\hline \multirow[t]{2}{*}{ Colostrum avoidance $(n=741$} & Yes & 164 & 22.1 \\
\hline & No & 577 & 77.9 \\
\hline \multirow[t]{9}{*}{ Reasons for colostrum avoidance $(n=164)$} & Causes abdominal cramp and diarrhea & 42 & 25.6 \\
\hline & Dirty & 38 & 23.2 \\
\hline & Cultural practice & 25 & 15.2 \\
\hline & Maternal medical illness & 13 & 7.9 \\
\hline & My breast has no milk & 14 & 8.5 \\
\hline & Not good for child growth & 5 & 3 \\
\hline & Infant not feed & 9 & 5.5 \\
\hline & Influence by others & 12 & 7.3 \\
\hline & Others* & 6 & 3.8 \\
\hline \multirow[t]{2}{*}{ Prelacteal feeding $(n=741)$} & Yes & 127 & 17.1 \\
\hline & No & 614 & 82.9 \\
\hline \multirow[t]{3}{*}{ Types of prelacteal feeding $(n=127)$} & Butter & 103 & 81.1 \\
\hline & Milk & 19 & 15 \\
\hline & Water & 5 & 3.9 \\
\hline \multirow[t]{8}{*}{ Reasons for prelacteal feeding $(n=127)$} & Breast milk causes thirsty & 3 & 2.4 \\
\hline & Good for child growth & 9 & 7.1 \\
\hline & Breastfeeding problem & 17 & 13.4 \\
\hline & Maternal medical illness & 18 & 14.2 \\
\hline & Cultural practices & 22 & 17.3 \\
\hline & To calm baby & 7 & 5.5 \\
\hline & To clean bowel and throat & 44 & 34.6 \\
\hline & Others ${ }^{* *}$ & 7 & 5.5 \\
\hline \multirow[t]{2}{*}{ Time of initiation of breastfeeding $(n=741)$} & More than $1 \mathrm{~h}$ & 290 & 39.1 \\
\hline & Within $1 \mathrm{~h}$ & 451 & 60.9 \\
\hline \multirow[t]{2}{*}{ BF counseling on timely initiation } & No & 293 & 39.5 \\
\hline & Yes & 448 & 60.5 \\
\hline
\end{tabular}

Key: Others* ${ }^{*}$ causes heart disease and constipation

Others $^{* *}=$ to prevent constipation, belief BF is not enough

Madhya Pradesh India [25, 30, 39, 44], respectively. This might be due to the fact that mothers who gave birth in health institutions might start breastfeeding immediately within $1 \mathrm{~h}$ after delivery and then have no time to discard colostrum. In addition, institutional delivery does not create a favorable environment for different sociocultural factors, like family influence. Besides, mothers who gave birth in health institutions receive advice from health professionals about the risks associated with colostrum avoidance which in turn helps them reduce the chance of colostrum avoidance [30,34].

Once more, the odd of colostrum avoidance was 7.35 times higher in mothers who had unfavorable attitude towards colostrum as compared to mothers who had favorable attitude towards colostrum (AOR $=7.35[95 \%$ CI; $3.89,13.91])$. There is no study consistent with this finding as per our review. This might be due to the fact that colostrum avoidance is traditional malpractice more associated with belief and if people hold unfavorable attitude towards colostrum, the probability of discarding it will be high.

This study has some limitations that ought to be taken into account when interpreting the results. First, crosssectional nature of this study may not show the temporal relationship between the dependent and independent variables. Second, ascertainment of colostrum avoidance was relied on the memory/information given by the study participants, which might be prone to recall bias. 
Table 4 Bivariable and multivariable logistic regression analysis showing factors associated with colostrum avoidance in Gozamen district, East Gojjam zone, North West Ethiopia, 2020 $(n=741)$

\begin{tabular}{|c|c|c|c|c|}
\hline Variables & Colostrum avoidance Yes No & $\operatorname{COR}(95 \% \mathrm{Cl})$ & AOR(95\%Cl) & $P$-value \\
\hline \multicolumn{5}{|l|}{ Husband occupation } \\
\hline Merchant & 637 & $0.13(0.36,0.46)$ & $0.81(0.07,8.66)$ & 0.973 \\
\hline Farmer & 120,446 & $0.22(0.08,0.56)$ & $0.62(0.08,4.57)$ & 0.641 \\
\hline Governmental and private employee & 954 & $0.13(0.04,0.43)$ & $0.37(0.04,3.44)$ & 0.625 \\
\hline Daily laborer & 108 & 1 & 1 & \\
\hline \multicolumn{5}{|l|}{ Age of the respondent } \\
\hline $15-25$ & 29,133 & $0.65(0.39,1.11)$ & $0.88(0.34,2.28)$ & 0.401 \\
\hline $26-35$ & 85,290 & $0.88(0.590,1.310)$ & $1.29(0.61,2.81)$ & 0.741 \\
\hline $36-45$ & 51,153 & 1 & 1 & \\
\hline \multicolumn{5}{|l|}{ Access to TV } \\
\hline No & 159,522 & $2.74(1.16,6.49)$ & $1.58(0.44,5.75)$ & 0.618 \\
\hline Yes & 654 & 1 & 1 & \\
\hline \multicolumn{5}{|l|}{ BF counseling during ANC } \\
\hline No & 76,271 & $2.30(1.49,3.57)$ & $1.28(0.64,2.56)$ & 0.793 \\
\hline Yes & 34,279 & 1 & 1 & \\
\hline \multicolumn{5}{|l|}{ Place of delivery } \\
\hline Health facility & 99,567 & $0.02(0.01,0.05)$ & $0.06(0.02,0.19)^{* *}$ & $<0.00$ \\
\hline Home & 669 & 1 & 1 & \\
\hline \multicolumn{5}{|l|}{ PNC visit } \\
\hline No & 57,117 & $2.07(1.42,3.02)$ & $0.87(0.42,1.82)$ & 0.280 \\
\hline Yes & 108,459 & 1 & 1 & \\
\hline \multicolumn{5}{|l|}{ BF counseling on timely initiation } \\
\hline No & 132,161 & $10.31(6.76,15.73)$ & $3.91(1.98,7.72)^{* *}$ & $<0.001$ \\
\hline Yes & 33,415 & 1 & 1 & \\
\hline \multicolumn{5}{|l|}{ Participation in pregnant woman forum } \\
\hline No & 136,186 & $9.83(6.35,15.23)$ & $2.59(1.30,5.14)^{*}$ & 0.013 \\
\hline Yes & 29,390 & 1 & 1 & \\
\hline \multicolumn{5}{|l|}{ Prelacteal feeding } \\
\hline No & 79,535 & $0.07(0.05,0.11)$ & $0.10(0.05,0.21)^{* *}$ & $<0.001$ \\
\hline Yes & 8641 & 1 & 1 & \\
\hline \multicolumn{5}{|l|}{ Time of BF initiation } \\
\hline More than $1 \mathrm{Hr}$ & 130,160 & $9.66(6.38,14.63)$ & $2.27(1.18,4.34)^{*}$ & 0.008 \\
\hline Within $1 \mathrm{Hr}$ & 35,416 & 1 & 1 & \\
\hline \multicolumn{5}{|l|}{ Attitude towards colostrum } \\
\hline Unfavorable & 9079 & $7.55(5.12,11.12)$ & $7.35(3.89,13.91)^{* *}$ & $<0.001$ \\
\hline Favorable & 75,497 & 1 & 1 & \\
\hline
\end{tabular}

NB: ${ }^{*}=P<0.05,{ }^{* *}=P<0.001,1=$ Reference category, Hosmer and Lemeshow goodness - of- fit $=P$ - value $=0.844, A O R$ Adjusted odds ratio, COR Crude odds ratio, $\mathrm{Cl}$ Confidence interval

\section{Conclusions}

This study revealed that colostrum avoidance is a common practice in the study area. Place of delivery, breast feeding counseling on timely initiation, time of BF initiation, prelacteal feeding, participation in pregnant woman forum, and attitude of mothers towards colostrum were significant independent predictors associated with colostrum avoidance. In order to reduce this practice, strengthening infant feeding counseling, promoting institutional delivery, timely initiation of breastfeeding, health education, and community advocating are recommended interventions. 


\section{Abbreviations}

ANC: Antenatal Care; AOR: Adjusted Odds Ratio; BF: Breast Feeding; CA: Colostrum Avoidance; Cl: Confidence Interval; EBF: Exclusive Breast Feeding; IYCF: Infant and Young Child Feeding; PCA: Principal Component Analysis; PLF: Pre Lacteal Feeding; PNC: Postnatal Care; SPSS: Statistical Package for Social Science; SSA: Sub Saharan Africa; TIBF: Timely Initiation of Breast Feeding; UOG: University of Gondar

\section{Acknowledgments}

First, we are highly indebted to Debre Markos town health office for permitting us to conduct the study and providing the necessary preliminary information while conducting this study.

We would also like to extend our appreciation to the data collectors, supervisors, and study participants for their devoted cooperation.

\section{Authors' contributions}

MG participated in the conception and design of the study, MG interpreted the data and drafted the initial manuscript. MA, ZNA, and TSA participated in commenting on the document. All authors read and approved the final manuscript, contributed the critical review and the content.

\section{Funding}

The author(s) received no specific funding for this work.

\section{Availability of data and materials}

The dataset analyzed during the current study available from the corresponding author on reasonable request.

\section{Declarations}

\section{Ethics approval and consent to participate}

Ethical clearance and approval was obtained from the Institutional Review Board of the University of Gondar. Then, official letter of support was written to Gozamen district health office. Additionally, written informed consent was sought and obtained from each participant after the purpose and objectives of the study were explained to them before they were recruited into the study. With regard to participants who were minors (participants under the age of 16 years), consent to participate in the study was sought and obtained from the parents/guardians before they were included in this study. Confidentiality was maintained at all levels of the study by avoiding the use of names and other identifiers. Participants' involvement in the study was on a voluntary basis; participants who were unwilling to participate in the study and those who wish to quit their participation were informed to do so without any restriction.

\section{Consent for publication}

Not applicable.

\section{Competing interests}

The authors declare that they have no competing interests.

\section{Author details}

'Department of Midwifery, College of Medicine and Health Sciences, Adigrat University, Adigrat, Ethiopia. 'Department of Women's and Family Health, School of Midwifery, College of Medicine and Health Sciences, University of Gondar, Gondar, Ethiopia. ${ }^{3}$ Department of Epidemiology and Biostatistics, Institute of Public Health, College of Medicine and Health Sciences, University of Gondar, Gondar, Ethiopia.

Received: 8 January 2021 Accepted: 29 March 2021

\section{Published online: 07 April 2021}

\section{References}

1. International LLI. What is colostrum? How does it benefit my baby? 2012. Available from: https://classtalkers.com/2012/04/22/what-is-colostrum-milk/.

2. Organization WH. Implementing the global strategy for infant and young child feeding. Geneva: 3-5 February 2003: meeting report: World Health Organization; 2003

3. Disha A, Rawat R, Subandoro A, Menon P. Infant and young child feeding (IYCF) practices in Ethiopia and Zambia and their association with child nutrition: analysis of demographic and health survey data. Afr J Food Agric Nutr Dev. 2012;12(2):5895-914

4. Godhia ML, Patel N. Colostrum-its composition, benefits as a Nutraceuticala review. Curr Res Nutr Food Sci J. 2013;1(1):37-47. https://doi.org/10.12944/ CRNFSJ.1.1.04

5. Liben ML, Abuhay T, Haile Y. The role of colostrum feeding on the nutritional status of preschool children in Afambo District, Northeast Ethiopia: descriptive cross sectional study. Eur J Clin Biomed Sci. 2016;2(6): 87-91. https://doi.org/10.11648/j.ejcbs.20160206.15.

6. Adugna DT. Women's perception and risk factors for delayed initiation of breastfeeding in Arba Minch Zuria, southern Ethiopia. Int Breastfeed J. 2014; $9(1): 1-8$.

7. Tamiru D, Belachew T, Loha E, Mohammed S. Sub-optimal breastfeeding of infants during the first six months and associated factors in rural communities of Jimma Arjo Woreda, Southwest Ethiopia. BMC Public Health. 2012;12:1-9.

8. Gartner L, Morton J, Lawrence R, Naylor A, O'Hare D, Schanler R. Breastfeeding and the use of human milk Pediatrics 115 (2): 496-506. Find this article online 2005.

9. Amele EA, Wondimeneh Demissie B, Desta KW, Woldemariam EB. Prelacteal feeding practice and its associated factors among mothers of children age less than 24 months old in southern Ethiopia. Ital J Pediatr. 2019:45:1-8.

10. Lamberti LM, Zakarija-Grković I, Walker CLF, Theodoratou E, Nair H, Campbell $\mathrm{H}$, et al. Breastfeeding for reducing the risk of pneumonia morbidity and mortality in children under two: a systematic literature review and meta-analysis. BMC Public Health. 2013;13(3):1-8.

11. Turin CG, Ochoa TJ. The role of maternal breast milk in preventing infantile diarrhea in the developing world. Curr Trop Med Rep. 2014;1(2):97-105.

12. Kaipu B, Fatima A, Pasha MM. A study on feeding practices of infants in the field practicing area of rural health training center, Santhiram medical college, Nandyal. J Evol Med Dent Sci. 2014:3(22):5960-4. https://doi.org/1 0.14260/jemds/2014/2689

13. Bekele $Y$, Mengistie B, Mesfine F. Prelacteal feeding practice and associated factors among mothers attending immunization clinic in Harari region public health facilities, eastern Ethiopia. Open J Prev Med. 2014:2014.

14. Tewabe T. Prelacteal Feeding Practices among Mothers in Motta Town, Northwest Ethiopia: A Cross-sectional Study. Ethiop J Health Sci. 2018; 28(4)4):393-402. https://doi.org/10.4314/ejhs.v28i4.5.

15. Bililign $N$, Kumsa $H$, Mulugeta $M$, Sisay $Y$. Factors associated with prelacteal feeding in north eastern Ethiopia: a community based crosssectional study. Int Breastfeed J 2016;11(1):1-7, 13, DOI: https://doi.org/1 0.1186/s13006-016-0073-x

16. Tilahun G, Degu G, Azale T, Tigabu A. Prevalence and associated factors of timely initiation of breastfeeding among mothers at Debre Berhan town, Ethiopia: a cross-sectional study. Int Breastfeed J. 2016;11(1):27-9. https://doi. org/10.1186/s13006-016-0086-5.

17. Hoche S, Meshesha B, Wakgari N. Sub-optimal breastfeeding and its associated factors in rural communities of Hula District, southern Ethiopia: a cross-sectional study. Ethiop J Health Sci. 2018;28(1):49-62. https://doi.org/1 0.4314/ejhs.v28i1.7.

18. Organization WH. Global health risks: mortality and burden of disease attributable to selected major risks: World Health Organization; 2009.

19. Lauer JA, Betrán AP, Barros AJ, de Onís M. Deaths and years of life lost due to suboptimal breast-feeding among children in the developing world: a global ecological risk assessment. Public Health Nutr. 2006;9(6):673-85. https://doi.org/10.1079/PHN2005891.

20. Unicef. Levels and trends in child mortality: Report 2010: Estimates developed by the UN Inter-Agency Group for Child Mortality Estimation: United Nations Children's Fund; 2010.

21. Ogbo FA, Agho K, Ogeleka P, Woolfenden S, Page A, Eastwood J, et al. Infant feeding practices and diarrhoea in sub-Saharan African countries with high diarrhoea mortality. PLoS One. 2017;12(2):e0171792. https://doi.org/1 0.1371/journal.pone.0171792.

22. Jones G, Steketee RW, Black RE, Bhutta ZA, Morris SS, Group BCSS. How many child deaths can we prevent this year? Lancet. 2003;362(9377):65-71. https://doi.org/10.1016/S0140-6736(03)13811-1.

23. Teshome B, Kogi-Makau W, Getahun Z, Taye G. Magnitude and determinants of stunting in children underfive years of age in food surplus region of Ethiopia: the case of west gojam zone. Ethiop J Health Dev. 2009;23(2). 
24. Aisha R, Batool F, Sultana S. Knowledge, attitude and practices about colostrum feeding among pregnant women in military hospital Rawalpindi of Pakistan. Open J Nurs. 2016;6(04):309-13. https://doi.org/10.4236/ojn.201 6.64032.

25. Yimer NB, Liben ML. Effects of home delivery on colostrum avoidance practices in north Wollo zone, an urban setting, Ethiopia: a cross sectional study. J Health Popul Nutr. 2018;37(1):1-7.

26. Weldesamuel GT, Atalay HT, Zemichael TM, Gebre HG, Abraha DG, Amare AK, Gidey EB, Alemayoh TT Colostrum avoidance and associated factors among mothers having children less than 2 years of age in Aksum town, Tigray, Ethiopia: a cross-sectional study 2017. BMC Res Notes. 2018;11: 1-7, 601, DOI: https://doi.org/10.1186/s13104-018-3712-z.

27. Indicators K. Mini demographic and health survey. 2019.

28. Institute EHaNR. National nutrition baseline survey for the National Nutrition Program of Ethiopia. Addis Ababa 2009/10.

29. Wolde TF, Ayele AD, Takele WW. Prelacteal feeding and associated factors among mothers having children less than 24 months of age, in Mettu district, Southwest Ethiopia: a community based cross-sectional study. BMC Res Notes. 2019;12:1-7.

30. Legesse M, Demena M, Mesfin F, Haile D. Factors associated with colostrum avoidance among mothers of children aged less than 24 months in Raya kobo district, North-Eastern Ethiopia: community-based cross-sectional study. J Trop Pediatr. 2015;61(5):357-63. https://doi.org/10.1093/tropej/fmv039.

31. Gebreyesus H, Girma E, Cherie N. Colostrum avoidance and associated factors among mothers of children aged less than 12 months in Kombolcha town, south Wollo zone, Ethiopia. Med Res Chronicles. 2017;4(05):545-59.

32. Seid AM, Yesuf ME, Koye DN. Prevalence of exclusive breastfeeding practices and associated factors among mothers in Bahir Dar city, Northwest Ethiopia: a community based cross-sectional study. Int Breastfeed J. 2013;8(1):1-8.

33. Setegn T, Belachew T, Gerbaba M, Deribe K, Deribew A, Biadgilign S. Factors associated with exclusive breastfeeding practices among mothers in Goba district, south East Ethiopia: a cross-sectional study. Int Breastfeed J. 2012;7(1):1-8.

34. Berde AS, Yalcin SS, Ozcebe H, Uner S, Caman OK. Determinants of pre-lacteal feeding practices in urban and rural Nigeria; a population-based cross-sectional study using the 2013 Nigeria demographic and health survey data. Afr Health Sci. 2017;17(3):690-9. https://doi.org/10.4314/ahs.v17i3.11.

35. Tewabe T, Mandesh A, Gualu T, Alem G, Mekuria G, Zeleke H. Exclusive breastfeeding practice and associated factors among mothers in Motta town, east Gojjam zone, Amhara regional state, Ethiopia, 2015: a crosssectional study. Int Breastfeed J. 2016;12:1-7.

36. Luo J, Prince DCJ, Mungai KF, James N. Knowledge, attitude, and practice of exclusive breastfeeding among mothers attending Masaka District hospital Kigali/Rwanda: a cross-section study. 2021

37. Rogers NL, Abdi J, Moore D, Nd'iangui S, Smith $\sqcup$, Carlson AJ, et al Colostrum avoidance, prelacteal feeding and late breast-feeding initiation in rural northern Ethiopia. Public Health Nutr. 2011;14(11):2029-36. https://doi. org/10.1017/S1368980011000073.

38. Raina SK, Mengi V, Singh G. Differentials in colostrum feeding among lactating women of block RS Pura of J and K: a lesson for nursing practice. Iran J Nurs Midwifery Res. 2012:17(5):386-9.

39. Raval D, Jankar D, Singh M. A study of breast feeding practices among infants living in slums of Bhavnagar city, Gujarat, India. Religion. 2011;2(2):19.

40. Kakati R, Rahman SJ, Borah M, Borah H. Colostrum feeding practices and its determinants among urban and rural mothers in Kamrup, Assam, India. Int J Res Med Sci. 2016;4(10):4567-72.

41. El-Gilany A-H, Abdel-Hady DM. Newborn first feed and prelacteal feeds in Mansoura, Egypt. Biomed Res Int. 2014;2014:1-7. https://doi.org/10.1155/2 $014 / 258470$

42. Tongun JB, Sebit MB, Ndeezi G, Mukunya D, Tylleskar T, Tumwine JK. Prevalence and determinants of pre-lacteal feeding in South Sudan: a community-based survey. Glob Health Action. 2018;11(1):1523304. https:// doi.org/10.1080/16549716.2018.1523304.

43. Alemu SM, Alemu YM, Habtewold TD. Association of age and colostrum discarding with exclusive breastfeeding in Ethiopia: systematic review and meta-analyses. bioRxiv. 2018:405225.

44. Meshram II, Rao KM, Krishna KS, Venkaiah K, Laxmaiah A, Brahmam GNV. Predictors of ante-natal care, delivery and infant feeding practices among rural women in Madhya Pradesh, India. Int J Med Public Health. 2014:4.

\section{Publisher's Note}

Springer Nature remains neutral with regard to jurisdictional claims in published maps and institutional affiliations.
Ready to submit your research? Choose BMC and benefit from:

- fast, convenient online submission

- thorough peer review by experienced researchers in your field

- rapid publication on acceptance

- support for research data, including large and complex data types

- gold Open Access which fosters wider collaboration and increased citations

- maximum visibility for your research: over $100 \mathrm{M}$ website views per year

At BMC, research is always in progress.

Learn more biomedcentral.com/submissions 